\title{
TWelfth AnNual Conference
}

\section{YUCOMAT 2010}

Hotel "Plaža", Herceg Novi, Montenegro, September 6-10, 2010

http://www.mrs-serbia.org.rs

\section{Programme and \\ The Book of Abstracts}

Organised by:

Materials Research Society of Serbia, and

Institute of Technical Sciences of the Serbian Academy of Sciences and Arts, Belgrade

\author{
under the auspices of \\ Federation of European Material Societies
}

and

Materials Research Society 
Title:

THE TWELFTH ANNUAL CONFERENCE

"YUCOMAT 2010"

Programme and The Book of Abstracts

Publisher: $\quad$ Institute of Technical Sciences of the Serbian Academy of Sciences \& Arts Knez Mihailova 35/IV; P.O. Box 377, 11000 Belgrade, Serbia Phone: +381 11 2185-437; Fax: + $381112185-263$

http://www.itn.sanu.ac.rs

Editor: $\quad$ Prof. Dr. Dragan P. Uskoković

Technical editor: Aleksandra Stojičić

Cover page: $\quad$ Aleksandra Stojičić and Milica Ševkušić

Copyright (C) 2010 Institute of Technical Sciences of the Serbian Academy of Sciences \& Arts
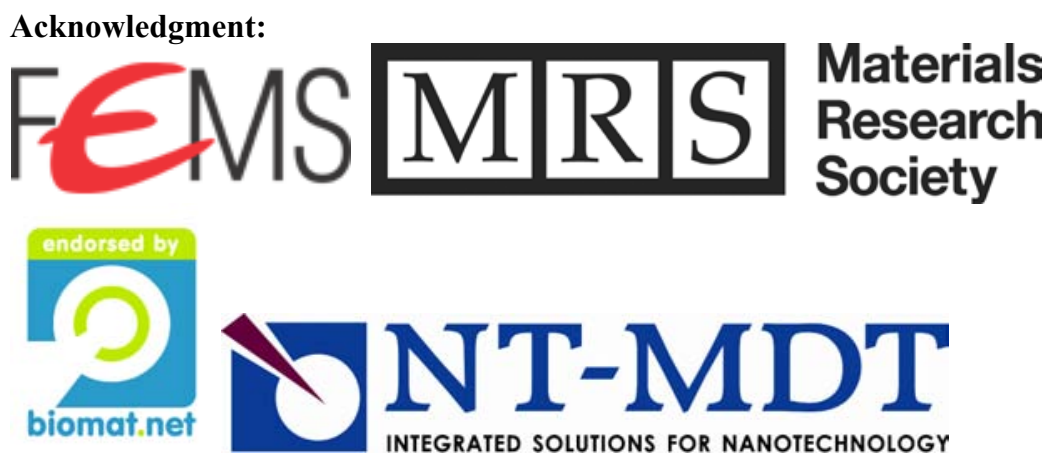

Printed in: $\quad$ Printing office "Čigoja" Studentski trg 15, 11000 Belgrade Phones: + 38111 2186-725; + 38111 2625-954

Circulation: 260 copies. The end of printing: July 2010. 


\title{
O.S.A.10
}

\section{PREPARATION OF LiFePO $/$ /C COMPOSITES BY CO-PRECIPITATION IN THE PRESENCE OF STEARIC ACID}

\author{
D. Jugović $^{1}$, M. Jović ${ }^{1}$, M. Mitrić ${ }^{2}$, N. Cvjetićanin ${ }^{3}$, D. Uskoković ${ }^{1}$ \\ ${ }^{I}$ Institute of Technical Sciences of the Serbian Academy of Sciences and Arts, Belgrade, Serbia, \\ ${ }^{2}$ Vinča Institute of Nuclear Sciences, Belgrade, Serbia, ${ }^{3}$ Faculty of Physical Chemistry, \\ University of Belgrade, Serbia
}

The olivine type compositions $\mathrm{LiMPO}_{4}(\mathrm{M}=\mathrm{Fe}, \mathrm{Mn}, \mathrm{Co})$ are among the most attractive materials for the positive electrode of lithium-ion battery. The benefits of using $\mathrm{LiFePO}_{4}$ are excellent cycle life, high structural stability, low cost and environmental friendliness. Its main limitation is low total electrical conductivity, which can be overcome by carbon coating and/or the achievement of a small and homogeneous particle size distribution. Here is presented a simple and inexpensive route for obtaining $\mathrm{LiFePO}_{4} / \mathrm{C}$ composites by aqueous co-precipitation of an $\mathrm{Fe}$ (II) precursor material in the presence of stearic acid and subsequent heat treatment at different temperatures. Stearic acid serves as both chelating agent and carbonaceous material. During pyrolytic degradation stearic acid decomposes to carbon while creating reductive atmosphere. The crystal structures of the powders were revealed by X-ray powder diffraction. It was shown that phase purity of the synthesized powders is very dependent on calcination temperature, as well as their electrochemical properties.

\section{O.S.A.11}

\section{PREPARATION AND SURFACE PROPERTIES $\mathrm{OF} \mathrm{CeO}_{2}-\mathrm{Nb}_{2} \mathrm{O}_{5}$ MIXED-OXIDE CATALYSTS}

\author{
D. Stošić ${ }^{1}$, V. Rakić ${ }^{2}$, S. Bennici ${ }^{1}$, A. Auroux ${ }^{1}$ \\ ${ }^{1}$ IRCELYON, UMR5256 CNRS- Université Lyon1, Villeurbanne, France, ${ }^{2}$ Faculty of \\ Agriculture, Department of Chemistry, University of Belgrade, Zemun, Serbia
}

The present work is focused on the synthesis and characterization of ceria-niobia mixed oxides. Mixed oxides with a wide range of niobia content were prepared by coprecipitation method with the aim to obtain given acid-base characteristics and subsequently to investigate the catalytic properties of the obtained materials. The synthesized solids have been characterized in terms of their structural, textural, and surface properties, including the acid-base and red-ox features, by a variety of techniques (BET, XRD, Raman spectroscopy, TG, and TPR-TPO). The acid-base properties were estimated by adsorption microcalorimetry measurements of ammonia and sulfur dioxide. All obtained mixed oxides showed specific amphoteric character influenced by relative amounts of the two component oxides. The obtained materials exhibited satisfactory homogeneity; the highest surface area was achieved for sample containing $73 \mathrm{wt} \%$ of $\mathrm{CeO}_{2}$. Only the fluorite structure of $\mathrm{CeO}_{2}$ was observed by XRD for all prepared mixed oxides. The crystallinity of samples decreased with increasing amount of $\mathrm{Nb}_{2} \mathrm{O}_{5}$. TPR-TPO results were strongly dependent on the bonding nature between the two oxides. In conclusion it was possible to tune the number of surface active sites by varying the ratio of ceria to niobia. 